\title{
SENSITIVITY ANALYSIS AND PARAMETER ESTIMATION FOR AN APPROXIMATE ANALYTICAL MODEL OF CANAL-AQUIFER INTERACTION APPLIED IN THE C-111 BASIN
}

\author{
I. Kisekka, K. W. Migliaccio, R. Muñoz-Carpena, Y. Khare, T. H. Boyer
}

\begin{abstract}
The goal of this study was to better characterize parameters influencing the exchange of surface water in south Florida's C-111 canal and Biscayne aquifer using the analytical model STWT1. A three-step model evaluation framework was implemented as follows: (1) qualitative parameter ranking by comparing two Morris method sampling strategies, (2) quantitative variance-based sensitivity analysis using Sobol's method, and (3) estimation of parameter posterior probability distributions and statistics using the Generalized Likelihood Uncertainty Estimator (GLUE) methodology. Results indicated that the original Morris random sampling method underestimated total parameter effects compared to the improved global Morris sampling strategy. However, parameter rankings from the two sampling methods were similar. For the STWT1 model, only four out of the six parameters analyzed were important for predicting water table response to canal stage and recharge fluctuations. Morris ranking in order of decreasing importance resulted in specific yield (ASY), aquifer saturated thickness (AB), horizontal hydraulic conductivity $(A K X)$, canal leakance (XAA), vertical hydraulic conductivity (AKZ), and half-width of canal (XZERO). Sobol's sensitivity indices for the four most critical parameters revealed that summation of first-order parameter effects was 1.0, indicating that STWT1 behaved as an additive model or negligible parameter interactions. We estimated parameter values of 0.07 to 0.14 for ASY, 11,000 to 14,300 $\mathrm{m} \mathrm{d}^{-1}$ for $A K X, 13.4$ to $18.3 \mathrm{~m}$ for $A B$, and 99.8 to $279 \mathrm{~m}$ for XAA. The estimated values were within the range of values estimated using more complex methods at nearby sites. The Nash-Sutcliffe coefficient of efficiency and root mean square error for estimated parameters ranged from 0.66 to 0.95 and from 4 to $7 \mathrm{~cm}$, respectively. This study demonstrates a simple and inexpensive way to characterize hydrogeological parameters controlling groundwater-surface interactions in any region with aquifers that are highly permeable without using standard pumping tests or canal drawdown experiments. Hydrogeological parameters estimated using this approach could be used as starting values in large-scale numerical simulations.
\end{abstract}

Keywords. Canal-aquifer interaction, GLUE method, Morris method, Parameter estimation, Sensitivity analysis, Sobol's method.

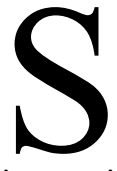
urface water in streams, canals, and rivers infiltrates into hydraulically connected aquifers during rising flood stage and is released back into surface water bodies during flow recession. This interaction between groundwater and surface water bodies occurs in virtually all types of landscapes (Winter et al., 1998). However, it is particularly critical in low-elevation coastal watersheds (e.g., southeastern Atlantic and Gulf

Submitted for review in November 2012 as manuscript number SW 10037; approved for publication by the Soil \& Water Division of ASABE in May 2013.

The authors are Isaya Kisekka, ASABE Member, Research Assistant, Department of Agricultural and Biological Engineering, University of Florida, Gainesville, Florida; Kati W. Migliaccio, ASABE Member, Associate Professor, Tropical Research and Education Center, University of Florida IFAS, Homestead, Florida; Rafeal Muñoz-Carpena, ASABE Member, Professor, and Yogesh Khare, ASABE Member, Graduate Student, Department of Agricultural and Biological Engineering, and Treavor H. Boyer, Assistant Professor, Department of Environmental Engineering Sciences, University of Florida, Gainesville, Florida. Corresponding author: Kati W. Migliaccio, 18905 SW 280th St., Homestead, FL 33031; phone: 305-246-7001, ext. 288; e-mail: klwhite@ufl.edu. coasts of the U.S.) with shallow water tables due to the high risk of flooding from large storms. As an example, south Florida's low-elevation coastal landscape has a shallow water table aquifer (Biscayne aquifer) that is hydraulically connected to an extensive canal network primarily constructed for flood control (Chin, 1990; Genereux and Guardiario, 1998). As part of flood control management in south Florida, pre-storm contingency planning normally involves artificially lowering the water table to create sufficient storage for the forecasted storm (Bolster et al., 2001). Canal stage lowering has to be done carefully to balance other freshwater uses such as ecosystem restoration in the Everglades and control of salt water intrusion.

Making the best flood control and water management decisions requires continuously improving our knowledge of factors such as canal bed conductance, aquifer specific yield, and aquifer saturated thickness as well as horizontal and vertical hydraulic conductivities, which may be used to characterize and predict aquifer responses to canal stage management. There are many ways of determining these 
physical parameters, e.g., using standard pumping tests and slug tests for quantifying hydraulic conductivity and specific yield (Freeze and Cherry, 1979) and canal drawdown tests for assessing aquifer hydrogeological parameters and canal bed conductance (Bolster et al., 2001). For regional studies, pumping and slug tests are expensive. In addition, they are particularly challenging for very permeable aquifers, such as the Biscayne aquifer, due to the large pumps and water conveyance pipes required to produce a large enough drawdown to be accurately measured (Fish and Stewart, 1991). Another approach that has been used for characterizing hydrogeological parameters in surface water-groundwater interaction problems is parameterization of numerical or analytical models. In this study, we focus on the latter, since numerical models could be computationally expensive when applied within a global sensitivity and parameter estimation framework (Vesselinov et al., 2012).

Many analytical models have been developed to describe the interaction between surface water bodies such as canals and groundwater aquifers (e.g., Hall and Moench, 1972; Serrano and Workman, 1998; Zlotnik and Huang, 1999; Moench and Barlow, 2000; Lal, 2001; Hantush, 2005). The main difference among these analytical models is the simplifying assumptions made in deriving a solution to the groundwater flow equation. In most analytical models, aquifer response to arbitrary stage and recharge fluctuations is simulated using the convolution integral (Olsthoorn, 2008). For this study, the approximate analytical solution developed by Barlow and Moench (1998) was selected because it is more generalized for many canal-aquifer configurations and boundary conditions and also accounts for the effect of both arbitrary canal stage and recharge variations. In addition, computer programs are available to facilitate implementation of the generalized unit-step response function with the convolution integral (http://water.usgs.gov/ogw/staq/). Examples of prior studies involving estimation of hydrogeological parameters using analytical models of canal-aquifer interaction include Bolster et al. (2001), Lal (2006), and Ha et al. (2007). Bolster et al. (2001) determined Biscayne aquifer specific yield using data from canal drawdown experiments and the analytical model developed by Zlotnik and Huang (1999) for partially penetrating streams with a low-permeability bed sediment layer in the absence of recharge. Lal (2006) determined bulk aquifer and canal resistance dimensionless parameters for the Biscayne aquifer using a coupled canalaquifer analytical model. Ha et al. (2007) applied an analytical model of river-aquifer interaction to estimate aquifer diffusivity and river bed resistance in the Mangyeong River floodplain, South Korea.

In prior investigations related to the Biscayne aquifer, sensitivity analysis was implemented using local sensitivity analysis techniques. Local sensitivity analysis is limited because (1) parameter interactions are not considered, (2) parameter importance is assessed only in the vicinity of mean parameter value, and (3) it is unreliable for nonlinear models (Frey and Patil, 2002). Global sensitivity analysis techniques overcome these limitations and provide more information on the response of linear and nonlinear model output to variations in model input factors. Global sensitivity analysis methods explore the entire parametric space of the model simultaneously for all model input factors, which allows them to capture first-order and higher-order parameter effects. Different global sensitivity analysis methods may be selected depending on the objective of the analysis, the number of uncertain input factors, and the computing time required for a single forward model simulation (Muñoz-Carpena et al., 2007; Saltelli et al., 2000). Saltelli et al. (2004) proposed that robust statistical frameworks for model evaluation should be based on global analysis techniques meeting the following requirements: (1) are model independent, i.e., can work with various models without the need for modification, (2) contain a screening method for qualitative identification of a subset of important model input factors, (3) contain a method that can quantitatively decompose model output variance in terms of first-order and higherorder input factor effects, and (4) can allow for uncertainty analysis through construction of output probability density functions (PDFs). The method of Morris (1991) provides a robust screening method, yet it requires few model simulations, while variance-based methods, such as Sobol's method, are robust for quantitative determination of firstorder and higher-order or interaction input factor effects (Sobol, 1993).

Morris (1991) proposed an effective screening sensitivity measure for identifying important parameters in models that have many parameters. The Morris method aims at identifying input factors whose effect on the model output is negligible, linear/additive, and nonlinear/involving interactions with other factors. The original Morris (1991) method is based on computing for each input factor, using a one-factor-at-a-time (OAT) approach, a number of incremental ratios called elementary effects (EE). Basic statistics are then calculated from the distributions of EE for each input factor, which are used to infer model output sensitivity to different parameters. Campolongo et al. (2007) observed that the sampling method employed in the original Morris (1991) method, which is based on random sampling of the input factor space, could lead to limited or non-optimum coverage of the input factor space, particularly for models with a large number of input factors. Campolongo et al. (2007) then proposed an improved sampling strategy that aims at better scanning of the input factor space without increasing the number of model executions. The philosophy behind the improved sampling strategy was to select $r$ trajectories in such a way as to maximize their dispersion in the input factor space. The improved sampling strategy guarantees a global dispersion of the selected trajectories but comes at a high computational cost.

Sobol's method (Sobol, 1993) is based on the computation of total sensitivity indices (TSI). The TSI of a given parameter includes main effects or first-order effects and all interaction effects involving a particular parameter (Sobol, 1993; Chan et al., 1997; Saltelli et al., 2000). The premise behind Sobol's method of computing sensitivity indices is decomposing the input-out relationship (i.e., model output) into summands of increasing dimensionality 
(Chan et al., 1997; Chan et al., 2000; Saltelli et al., 2000). The resulting equation is complex and is solved using Monte Carlo numerical integration to obtain sensitivity indices. One of the drawbacks of this method is its computational cost, especially for models with many uncertain input factors.

Another key component of model evaluation is parameter estimation or model calibration using measured system responses. Beven (2006) demonstrated that there are multiple models structures and optimum parameter sets that could be used for simulating a hydrologic system. This phenomenon is known as equifinality, and it arises from the fact that models are imperfect representations of natural systems due to various sources of uncertainty. Several methods have been developed for parameter uncertainty. Among the most popular is the General Likelihood Uncertainty Estimator (GLUE). The GLUE methodology rejects the idea of a single optimal solution and adopts the concept of equifinality of model input factors and model structure; thus, there are multiple model structures and input factors that can be used to simulate a natural system (Beven and Binley, 1992). With regard to the uncertain model parameters, in the GLUE analysis the prior set of model parameters is divided into a set of acceptable solutions and another set of non-acceptable solutions. The degree of membership to either set is determined by assessing the extent to which the model simulations fit the observed data, which in turn is determined by a subjective likelihood function, e.g., the Nash-Sutcliffe coefficient of efficiency (NSE). With regard to assessing parameter uncertainty, the outputs from GLUE are posterior PDFs and cumulative density functions (CDFs) describing parameter statistics.

The goal of this study was to use global sensitivity and global parameter estimation techniques with an analytical model of canal-aquifer interaction to better characterize model parameters influencing the exchange of water between the C-111 canal and the Biscayne aquifer in south Florida. The objectives were to: (1) apply the Morris screening technique using two sampling approaches to identify a subset of the parameters to which model output was most sensitive, (2) apply Sobol's variance-based global sensitivity analysis technique on a subset of parameters obtained from the Morris method to quantify first-order (only due to a given parameter) and total effects (the parameter and its interactions with other parameters) sensitivity indices, and (3) apply the GLUE methodology to obtain values of parameter sets that produce acceptable results (i.e., parameters that result in the closest agreement between predicted and measured water table elevation measured using the Nash-Sutcliffe coefficient of efficiency).

\section{MATERIALS AND MethodS}

\section{STUDY AREA}

The study area was an agricultural area of approximately $17 \mathrm{~km}^{2}$ located within the C-111 basin in Homestead, Florida, in southern Miami-Dade County (fig. 1). The hydrogeologic system at the study site consists of the Biscayne aquifer bordered by two canals (C-111 and C111E) separated by a distance of approximately $3.5 \mathrm{~km}$ (fig. 1) and managed by the South Florida Water Managements District (SFWMD). The Biscayne aquifer is a highly permeable, unconfined aquifer with hydraulic conductivities reported to exceed $10,000 \mathrm{~m} \mathrm{~d}^{-1}$ and serves as the principle source of drinking water for over 3 million people in Miami-Dade, Broward, and the southern part of West Palm counties in southeast Florida (Genereux and Guardiario, 1998). The Biscayne aquifer is wedge-shaped, increasing in thickness from the western boundary of Miami-Dade and Broward Counties to a thickness of approximately $60 \mathrm{~m}$ near the coast. At our study site, the aquifer consists of two formations: the Miami Limestone formation and the underlying Fort Thompson Limestone formation (Fish and Stewart, 1991). Aquifer thickness at our study site has not been measured, but Genereux and Guardiario (1998) reported a thickness of $13.6 \mathrm{~m}$ for a nearby site west of our current study site, with roughly onethird accounted for by the Miami Limestone formation.

Canal C-111 was constructed in 1967 as the principle flood control canal for south Miami-Dade County and partially penetrates the Biscayne aquifer to a depth of approximately $5 \mathrm{~m}$ (i.e., $4 \mathrm{~m}$ through the Miami Limestone formation and $1 \mathrm{~m}$ into the Fort Thompson Limestone formation). Flow in C-111 is south toward Florida Bay, and the topography is essentially flat, ranging between 1.1 and $2.2 \mathrm{~m}$ National Geodetic Vertical Datum (NGVD) 29. The width of the canal increases from north to south, with an average width of approximately $29 \mathrm{~m}$ at the S-177 gated spillway. Currently, very little is known about hydraulic properties of the canal bed sediment in the lower C-111; however, several studies have documented the presence of a low-permeability canal bed sediment layer, a mixture of carbonate mud and natural organic matter, in several canals within the C-111 basin (Chin, 1991; Genereux and Guardiario, 1998; Merkel, 2000).

\section{HYdRologic DATA Monitoring}

Data from six groundwater observations wells were used (fig. 1; table 1). The observation wells were separated into two groups: group 1 with wells $\mathrm{VC} 1, \mathrm{VC} 2$, and $\mathrm{AK} 5$, and group 2 with wells AK6, C-111AE, and C-111AW (fig. 1). Each group was assigned a different canal stage based on its proximity to the headwater or tail waters of the S-177 gated spillway (fig. 1). Group 1 was assigned to the C-111 headwater canal stage, while group 2 was assigned to the C-111 tail water canal stage. Observation wells C-111AE and $\mathrm{C}-111 \mathrm{AW}$ were constructed and maintained by the SFWMD, while the other four sites (VC1, VC2, AK5, and AK6) were constructed and maintained by University of Florida (UF) IFAS. The UF wells were constructed using a $50.8 \mathrm{~mm}$ (nominally 2 in.) PVC casing, which was inserted into a $101.6 \mathrm{~mm}$ bore of $6 \mathrm{~m}$ depth. The screen size was $0.254 \mathrm{~mm}$ (nominally $0.1 \mathrm{in}$.) with a length of $1.5 \mathrm{~m}$. The well was backfilled using 20/30 silica sand filter pack up to a depth of $60 \mathrm{~cm}$ above the screen. A $2.5 \mathrm{~m}$ layer of 30/65 fine sand was placed above the filter pack. A $6 \mathrm{~m}$ steel rod was used by gently dropping it into the annular gap to en- 


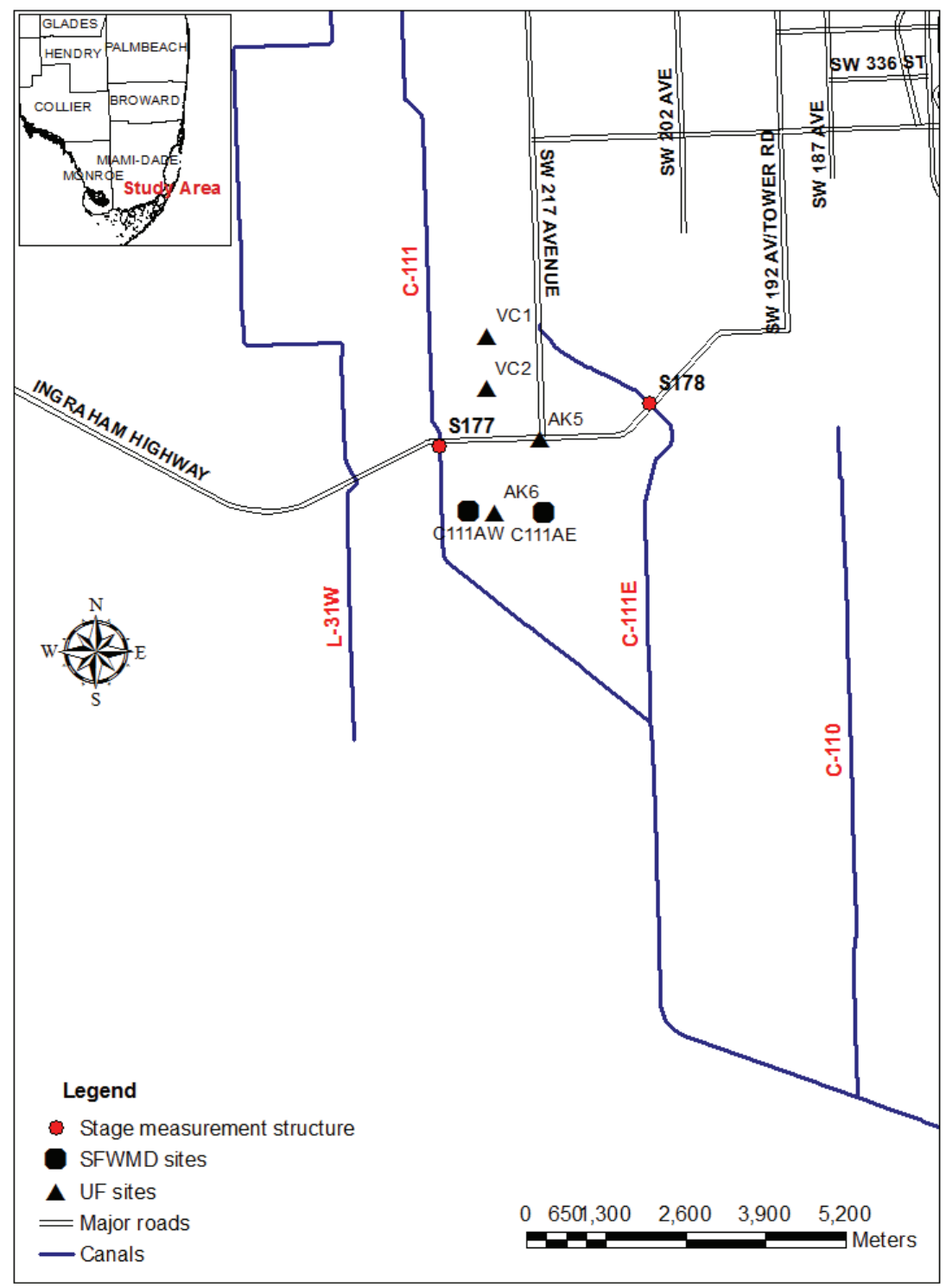

Figure 1. Map of the study area showing University of Florida (UF) and South Florida Water Management District (SFWMD) experimental sites and the SFWMD canal network in the lower $\mathrm{C}-111$ agricultural basin.

sure the space was uniformly backfilled. The well was filled with Portland type I cement grout to a depth of $35 \mathrm{~cm}$ below the ground surface. The top of the well was completed with $40 \mathrm{~cm}$ cast-iron manhole. The UF wells were equipped with level loggers (Levelogger, Gold Solinst Canada, Ltd., Georgetown, Ontario, Canada) to record water table elevation every $15 \mathrm{~min}$, although daily averages were used in the modeling. Atmospheric corrections were accounted for using a STS Barologger (Solinst Canada, Ltd.) in well AK6 (fig. 1). Data were downloaded from the wells weekly; as a quality control procedure, water table elevations were also measured manually with a laser water level well meter (model 102, Solinst Canada, Ltd.). Elevations at the top of the well manholes were measured

Table 1. Monitoring groundwater wells with descriptors.

\begin{tabular}{|c|c|c|c|c|c|c|}
\hline & \multicolumn{3}{|c|}{ Distance from } & \multicolumn{2}{|c|}{ Location } & \multirow{2}{*}{$\begin{array}{c}\text { Ground Elevation } \\
(\mathrm{NGVD} 29, \mathrm{~m})\end{array}$} \\
\hline & Well & C-111 Canal (m) & Installer ${ }^{[\mathrm{a}]}$ & Latitude & Longitude & \\
\hline \multirow[t]{3}{*}{ Group 1} & VC1 & 1000 & UF & 25.41883 & -80.550041 & 2.07 \\
\hline & $\mathrm{VC} 2$ & 1000 & UF & 25.41110 & -80.550375 & 1.86 \\
\hline & $\mathrm{AK} 5$ & 2000 & UF & 25.40347 & -80.541933 & 2.07 \\
\hline \multirow[t]{3}{*}{ Group 2} & AK6 & 1000 & UF & 25.39283 & -80.549543 & 2.23 \\
\hline & C-111AE & 2000 & SFWMD & 25.39261 & -80.541605 & 1.19 \\
\hline & C-111AW & 500 & SFWMD & 25.39317 & -80.553724 & 1.21 \\
\hline
\end{tabular}

a] SFWMD = South Florida Water Management District, and UF = University of Florida. 
with a laser level with reference to a benchmark at $1.21 \mathrm{~m}$ NGVD29 elevation near well C-111AE. Details about the SFWMD wells are available at: www.sfwmd.gov/ dbhydroplsq1/show_wilma_info.report_process. Water table elevation data for wells $\mathrm{C}-111 \mathrm{AE}$ and $\mathrm{C}-111 \mathrm{AW}$ were processed by SFWMD and published on its online environmental database DBHydro (www.sfwmd.gov/ dbhydroplsql/show_dbkey_info.main_menu).

In south Florida, most of the rainfall is received from the end of May to the beginning of November and is dominated by conventional or tropical rainfall forming processes. Under such rainfall forming processes, tipping buckets may fail to accurately represent the orientation of the rainfall front or fail to capture the entire rainfall events (Pathak, 2008). To minimize the uncertainty associated with the spatial variability of rainfall in south Florida, gaugeadjusted NEXRAD (Next Generation Radar) rainfall data were used. Skinner et al. (2008) showed that both NEXRAD data and point tipping-bucket measurements had limitations, but the best of the two measurement methods was realized by using rain gauge data to adjust NEXRAD values. Gauge-adjusted NEXRAD rainfall data on a $2 \times$ $2 \mathrm{~km}$ grid were obtained from SFWMD.

Ground surface potential evapotranspiration $\left(\mathrm{ET}_{0}\right)$ was computed from micrometeorological data obtained from a Florida Automated Weather Network (FAWN; http://fawn. ifas.ufl.edu) station located approximately $10 \mathrm{~km}$ northeast of the study site at the Tropical Research and Education Center, Homestead, Florida. The ASCE standardized Penman-Monteith equation and the Ref-ET tool by Allen (2011) were used to estimate $\mathrm{ET}_{0}$ values.

Canal stage data were measured at the S-177 gated spillway. Daily headwater and tailwater canal stage data were used. Canal stage data were measured by SFWMD and are available at: www.sfwmd.gov/dbhydroplsql/show dbkey_info.main_menu.

\section{Analytical Model}

The governing equation for two-dimensional groundwater flow (in a vertical plane) in a water table aquifer is expressed as equation 1 (Barlow and Moench, 1998). The initial condition is expressed as equation 2 . Equation 3 represents the right boundary condition (BC) as the aquifer extends to infinity. Equation 4 represents the head-dependent boundary flux at the canal-aquifer interface. Equation 5 represents the boundary at the water table, while equation 6 represents the no-flow bottom BC:

$$
\begin{gathered}
\frac{\partial^{2} h}{\partial x^{2}}+\frac{K_{z}}{K_{x}} \frac{\partial^{2} h}{\partial z^{2}}=\frac{S_{s}}{K_{x}} \frac{\partial h}{\partial t} \\
h(x, z, 0)=h_{i} \\
h(\infty, z, t)=h_{i} \\
\frac{\partial h}{\partial x}\left(x_{0}, z, t\right)=-\frac{1}{a}\left[h_{0}-h\left(x_{0}, z, t\right)\right], a=\frac{K_{x} d}{K_{s}}
\end{gathered}
$$

$$
\begin{gathered}
\frac{\partial h}{\partial z}(x, b, t)=\frac{S_{y}}{K_{z}} \frac{\partial h}{\partial t} \\
\frac{\partial h}{\partial z}(x, 0, t)=0
\end{gathered}
$$

where $K_{x}$ and $K_{z}$ are horizontal and vertical hydraulic conductivities $\left(\mathrm{m} \mathrm{d}^{-1}\right), S_{s}$ is the specific storage $\left(\mathrm{d}^{-1}\right), x$ is the distance in the horizontal direction $\left(\mathrm{m} ; x_{o}<x<\infty\right.$, where $x_{o}$ is the distance from the middle of the canal to the canal aquifer boundary), $z$ is the distance in the vertical direction ( $\mathrm{m}$; $0<z<b$, where $b$ is the saturated thickness of the aquifer), $h_{i}$ is the initial water level in the aquifer (m), $a$ is the canal leakance $(\mathrm{m}), K_{s}$ is the canal bed sediment hydraulic conductivity $\left(\mathrm{m} \mathrm{d}^{-1}\right), d$ is the thickness of the sediment layer $(\mathrm{m})$, and $S_{y}$ is the specific yield.

Barlow and Moench (1998) derived an analytical solution to the boundary value problem in equations 1 through 6 for an instantaneous unit-step change in canal stage relative to the water level in the adjacent aquifer, expressed as equation 7 :

$$
\begin{aligned}
& \overline{h_{D}}= \\
& 2 \sum_{n=0}^{\infty} \frac{W_{n} \exp \left[-q_{n}\left(x_{D}-1\right)\right] \sin \left(\varepsilon_{n}\right) \cos \left(\varepsilon_{n} z_{D}\right)}{\left\{1+A q_{n} \tanh \left[q_{n}\left(x_{L D}-1\right)\right]\right\} p\left[q_{n}+0.5 \sin \left(2 \varepsilon_{n}\right)\right]} \\
& q_{n}=\left(\varepsilon_{n}^{2} \beta_{0}+p\right)^{0.5}, \varepsilon_{n} \tan \left(\varepsilon_{n}\right)=\frac{p}{\sigma \beta_{0}}, \beta_{0}=\frac{K_{z} x_{0}^{3}}{K_{x} b}, \\
& \sigma=\frac{S_{s} b}{S_{y}}, A=\frac{K_{x} d}{K_{s} x_{0}}, x_{D}=\frac{x}{x_{o}}, x_{L D}=\frac{x_{L}}{x_{o}},
\end{aligned}
$$

where $\bar{h}_{D}$ is a dimensionless Laplace transform unit-step response for hydraulic head in a water table aquifer, $W_{n}$ is a parameter related to aquifer width in the Laplace transform solution (this term goes to 1 for semi-infinite aquifers), $x_{L}$ is the extent of finite aquifer, $p$ is the Laplace transform variable, and $A$ is dimensionless canal bank leakance.

Equation 7 is combined with the convolution integral (eq. 8) to predict water table responses to arbitrary changes in canal stage and recharge (difference between rainfall and $\mathrm{ET}_{\mathrm{o}}$ ). The discretized convolution equation was expressed by Barlow and Moench (1998) as:

$$
\begin{gathered}
h(x, z, j)=h_{i}+\sum_{k=2}^{J} F^{\prime}(k-1) h_{D}(x, z, j-k+1) \Delta t \\
F^{\prime}(k-1)=\frac{F(k)-F(k-1)}{\Delta t}
\end{gathered}
$$

where $j$ is the upper limit of time integration, $k$ is the time step, $\Delta t$ is the time step size (days), $F^{\prime}(k-1)$ is the time rate of change of canal stage and recharge $\left(\mathrm{m} \mathrm{d}^{-1}\right), F(k-1)$ is the canal stage or recharge at time step $(k-1)$, and $F(k)$ is the canal stage or recharge at time step $k$. The Biscayne aquifer was conceptualized as a semi-infinite water table aquifer with a thin vadose zone into which water instantaneously 
entered or exited. The aquifer was also assumed to be bordered by a fully penetrating canal (C-111) with a semipervious sediment layer. The time step size was one day. Since the solution obtained from equation 8 is in the Laplacian domain, it was inverted back to the real-time domain using the Stehfest algorithm (Stehfest, 1970). The software STWT1, developed by Barlow and Moench (1998), was used to implement the computation of water table head.

To simulate water table response to canal stage and recharge variations using the STWT1 model requires a total of eleven input factors (refers to parameters and inputs). For the simulation, we considered parameters that we did not measure to be uncertain $\left(K_{x}, K_{z}, S_{y}, b, K_{s}, d\right.$, and $\left.x_{o}\right)$, while the inputs ( $x, h_{i}$, recharge, and well screen length) that were measured were considered certain. Canal bed sediment hydraulic conductivity and thickness are included in a single parameter called canal leakance (eq. 4). The two STWT1 outputs are water table head and canal seepage. However, sensitivity analysis and parameter estimation were based only on water table head, since canal seepage was not measured.

\section{GLOBAL SENSITIVITY ANALYSIS}

Two global sensitivity analysis (GSA) methods were implemented: (1) parameter screening using the Morris method and (2) variance-based global sensitivity analysis (Sobol's method). The analysis was implemented in the following steps: (1) PDFs for uncertain parameters were constructed using data from the literature; (2) input parameter sets were obtained by sampling the multivariate input distributions according to the selected global method (i.e., Morris sampling for initial parameter screening and Sobol's sampling for quantitative determination of sensitivity indices); (3) STWT1 model simulation was executed for each input parameter set; (4) using model output (i.e., NSE) for all parameter sets, Morris sensitivity analysis was performed in order to obtain qualitative ranking of parameters; and (5) using a subset of critical parameters identified in step 4, steps 2 to 4 were repeated and quantitative first-order and higher-order (parameter interaction) sensitivity indices were determined using Sobol's method. Sensitivity analysis was implemented using SimLab v2.2 (SimLab, 2004). We interfaced SimLab with STWT1 using a program written in Matlab (R2012a, The Mathworks, Inc., Natick, Mass.). Using SimLab's preprocessor and the PDFs and statistics of the uncertainty model input parameters in table 2, together with the sampling method selected, a sample input file was generated. A sample input file is a matrix comprising multiple input parameter sets obtained from random sampling of probability distributions. The Matlab interface program was used to automatically execute the model for each parameter set and to produce outputs in the desired SimLab format for post-processing, i.e., sensitivity analysis. For each simulation, the Matlab program was also used to calculate the NSE (between simulated and measured water table elevation) and root mean square error (RMSE), which were used as the model outputs in the sensitivity analysis.

\section{MORRIS METHOD}

The finite distribution of EE associated with each input factor $\left(F_{i}\right)$ is obtained by randomly sampling the model input factor space. For each input factor, Morris (1991) proposed two sensitivity measures: $\mu$, which assesses the overall effect of the factor on model output, and $\sigma$, which indicates the effects of a factor's interactions with other factors (i.e., nonlinear effects). To estimate $\mu$ and $\sigma$, Morris (1991) suggested sampling $r$ elementary effects from $F_{i}$ distribution of each input factor, using a design that constructs $r$ trajectories of $(k+1)$ points in the input factor space, providing $k$ elementary effects, one for each factor. In the original Morris (1991) method, the number of model executions $(N)$ is computed as equation 10 :

$$
N=r(k+1)
$$

Generally in the original Morris method, $r$ is taken in the range of 4 to 10 (Saltelli et al., 2009). For this study, $r$ of 8 and $k$ of 6 were used, resulting in 56 model simulations. Morris (1991) proposed plotting these two measures on a $\mu-\sigma$ Cartesian plane to aid interpretation. Campolongo et al. (2007) suggested using absolute values of elementary effects $\left(\mu^{*}\right)$ to avoid the cancelling effects of opposite signs in case of non-monotonic models. This was implemented in SimLab.

To compare the performance of the two Morris sampling methods, we repeated Morris screening using the improved sampling strategy proposed by Campolongo et al. (2007). The improved sampling strategy was implemented by initially generating a high number of Morris trajectories $(M \approx 500$ to 1000), followed by choosing the best $r$ trajectories (e.g., $r=10$ ) with the greatest spread within the input factor space. A quantity $D$ representing the sum of distances between couples of trajectories belonging to the same combination was calculated, following the procedure of Campolongo et al. (2007). D was calculated for all possible combinations of $r$ trajectories, which results in high computational cost, especially for large models. A combination of trajectories corresponding to the global

Table 2. Summary of STWT1 model uncertain parameters and their probability distributions.

\begin{tabular}{|c|c|c|c|c|c|}
\hline Parameter & $\begin{array}{c}\text { Base } \\
\text { Value }\end{array}$ & $\begin{array}{l}\text { Range or } \\
\text { Standard } \\
\text { Deviation }\end{array}$ & Units & PDF & Reference \\
\hline Horizontal hydraulic conductivity $\left(K_{x}\right)$ & 12187 & 1844 & $\mathrm{~m} \mathrm{~d}^{-1}$ & Lognormal & Fish and Stewart (1991) \\
\hline Vertical hydraulic conductivity $\left(K_{z}\right)$ & 614 & 78 to 1587 & $\mathrm{~m} \mathrm{~d}^{-1}$ & Uniform & Genereux and Guardiario (1998) \\
\hline Stream bank leakance $(a)$ & 217 & 83 to 360 & - & Uniform & Genereux and Guardiario (1998) \\
\hline Specific yield $\left(S_{y}\right)$ & 0.15 & 0.05 to 0.57 & - & Triangular & Bolster et al. (2001) \\
\hline Saturated thickness $(b)$ & 13.6 & 8 to 19 & $\mathrm{~m}$ & Uniform & Bolster et al. (2001) \\
\hline Half-width of canal $\left(x_{0}\right)$ & 15.5 & 10 to 21 & $\mathrm{~m}$ & Uniform & Measured \\
\hline
\end{tabular}


maximum $D$ is selected as the best set of $r$ trajectories. To overcome the computational cost associated with the improved sampling strategy, Ruano et al. (2012) proposed a sampling strategy that considerably reduces the computational cost required to select optimum $r$ trajectories out of $M$ by developing a procedure that does not take into account all possible combinations of $r$ trajectories but selects a combination of $r$ trajectories that are as close as possible to the highest spread ones. This sampling strategy does not guarantee that the final trajectories selected represent the maximum distance between them, but it ensures that the distances are at least locally maximized. Since the issue of computational cost was not an issue in this study, given the small size of the STWT1 model, we applied the improved sampling strategy (with $r=10$ ) of Campolongo et al. (2007), which ensured a global distance $D$ for the selected optimum set of trajectories. The improved sampling strategy was implemented using Matlab algorithms. The Morris sensitivity analysis was developed by Saltelli et al. (2008) and is available at: http://sensitivityanalysis.jrc.it/software/index.htm.

\section{SOBOL'S METHOD}

The difference between first-order and total sensitivity indices was used as a measure of interaction effects associated with an uncertain input parameter. TSI are a more reliable measure of the overall effect of a factor on model output than first-order sensitivity indices, especially when the interactions between the parameters are considerable (Saltelli et al., 2000). The number of model simulations required to implement Sobol's method for computation of first-order and total sensitivity indices is expressed as equation 11:

$$
N=2 n(k+1)
$$

where $N$ is the number of model executions, $n$ is the sample size, and $k$ is the number of input factors. Saltelli et al. (2005) recommend $n=500$ to 1000 to get stable results. For this study, we used $n=512$, and $k$ depended on the number of important parameters identified from the Morris screening.

\section{GLUE METHODOLOGY}

The GLUE methodology was implemented in four steps: steps 1 to 3 were similar to those discussed earlier (under "Global Sensitivity Analysis") for computing Sobol sensitivity indices. In step 4, an evaluation procedure was performed for every single simulation performed in step 3 . The simulations, and thus the parameter sets, were rated according to the degree to which the simulated water table elevation matched the measured water table elevation. The NSE was used as the likelihood measure and was calculated by the Matlab code described earlier outside of the GLUE analysis. Simulations with NSE close to 1 were accepted, while simulations with NSE close to zero were rejected. Using the likelihood measure assigned to all acceptable parameter sets, a discrete joint likelihood function was generated (eq. 12):

$$
L(\theta \mid y)=\left(1-\frac{\sigma_{\varepsilon}^{2}}{\sigma_{o}^{2}}\right), \sigma_{\varepsilon}^{2} \geq \sigma_{o}^{2} \Rightarrow L(\theta \mid y)=0
$$

where $\sigma_{\varepsilon}^{2}$ is the error variance, and $\sigma_{o}^{2}$ is the variance of the observed water table elevation, NSE takes a value of 1 for a perfect model fit; a value of less than 0 implies that the mean value of the observed data would be a better predictor than the simulation model (Krause et al., 2005; Stedinger et al., 2008). Since the discrete joint likelihood function can only be illustrated in a maximum of three dimensions, scatter plots (dot plots) were used to illustrate the estimated parameters. Finally, the likelihoods were projected onto the parameter axis, and discrete posterior PDFs and corresponding CDFs were generated for each parameter. We implemented the GLUE methodology using a software package called GLUEWIN (Ratto and Saltelli, 2001). Within the GLUEWIN environment, only the sample file, model output file, and likelihood file were required to estimate parameter posterior distributions and statistics.

\section{RESULTS AND DisCUSSION \\ PARAMeTER SCREening: Morris Method}

The rankings of the relative importance of STWT1 input parameters based on the Morris method and two sampling techniques are presented in figures 2 and 3, with the greater the separation from the origin of the $\mu^{*}$ versus $\sigma$ plane corresponding to greater importance of the parameter. The number of STWT1 model parameters identified as important for predicting water table elevation using NSE as our model output measure was reduced from six to four in both sampling techniques.

Overall, Morris screening of parameters based on the random sampling technique and the improved sampling strategy by Campolongo et al. (2007) were similar (figs. 2 and 3). However, the magnitudes of the sensitivity measures $\mu^{*}$ and $\sigma$ were higher for the improved sampling strategy, particularly for $\sigma$. This indicates that ensuring maximum dispersion of trajectories within the model input factor space was able to capture effects of parameters on model output better than the random sampling techniques implemented in the original Morris (1991) method. It is worth noting that all the STWT1 parameters within the $\mu^{*}$ $\sigma$ plane for both sampling techniques were below the imaginary $1: 1$ line within the $\mu^{*}-\sigma$ plane, indicating that the parameter effects were primarily first-order, with minimum parameter interactions. Global sensitivity analysis of the STWT1 model using the Morris method shows a strong influence of specific yield (ASY) at all the six wells (figs. 3 and 4), where ASY is farthest along the $\mu^{*}$-axis and highest along the $\sigma$-axis. As specific yield characterizes the increase in water table elevation or drawdown due to recharge or pumping, respectively, its strong influence on predicting water table elevation is expected. Others have reported similar findings. Using oneat-a-time (OAT) local sensitivity analysis methods and a two-dimensional MODFLOW model for the Biscayne 


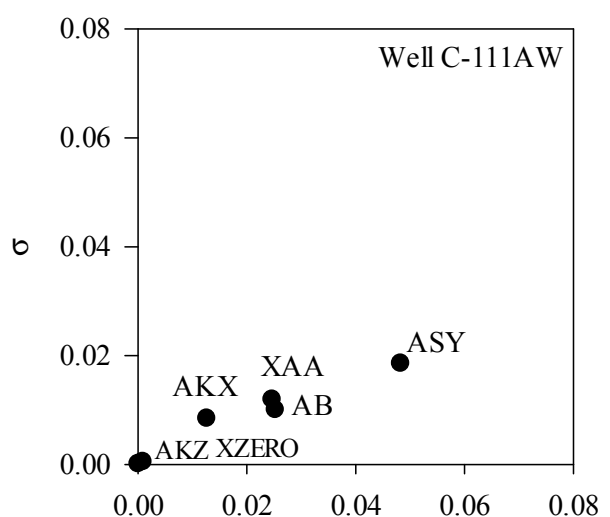

$\mu *$

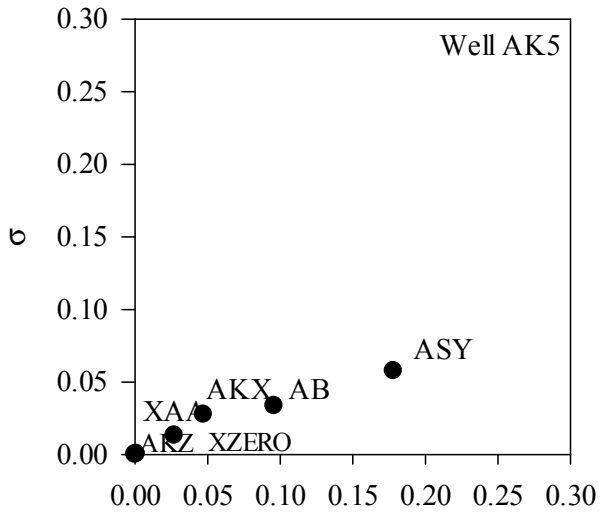

$\mu *$

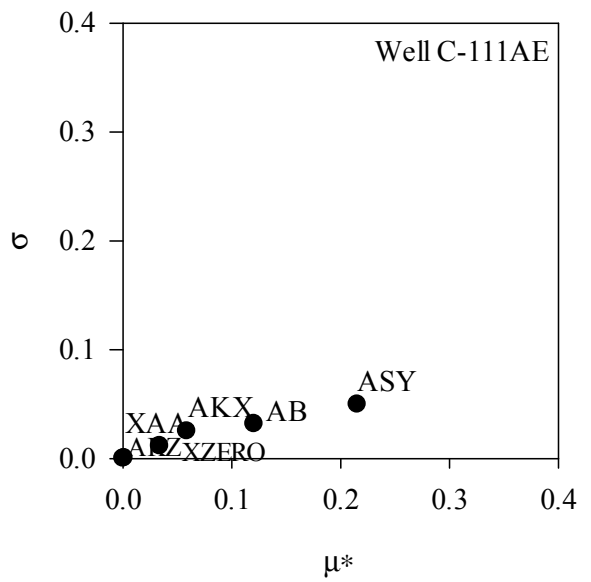

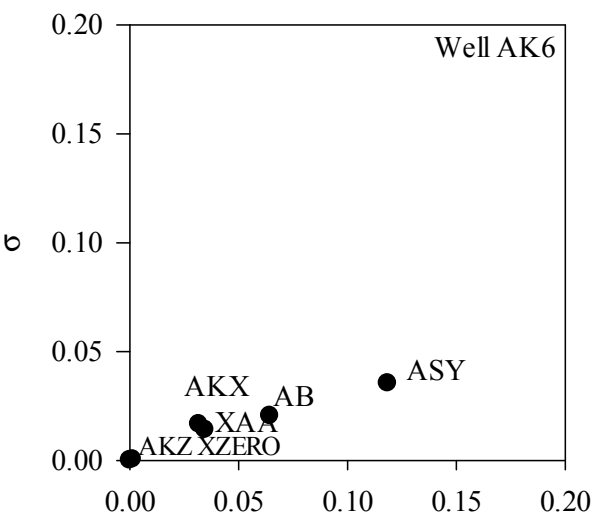

$\mu *$

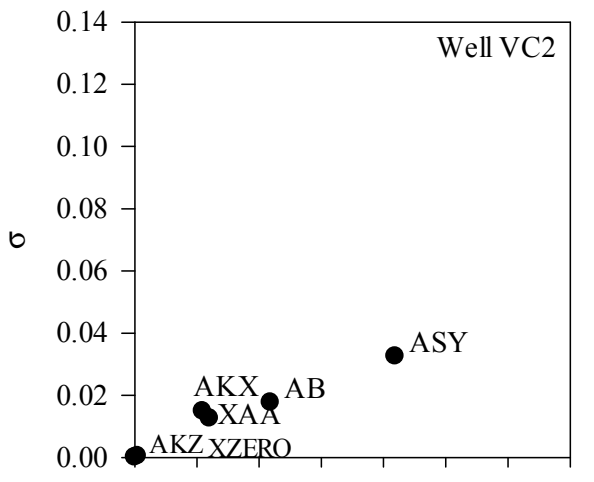

$\begin{array}{llllllll}0.00 & 0.02 & 0.04 & 0.06 & 0.08 & 0.10 & 0.12 & 0.14\end{array}$

$\mu *$

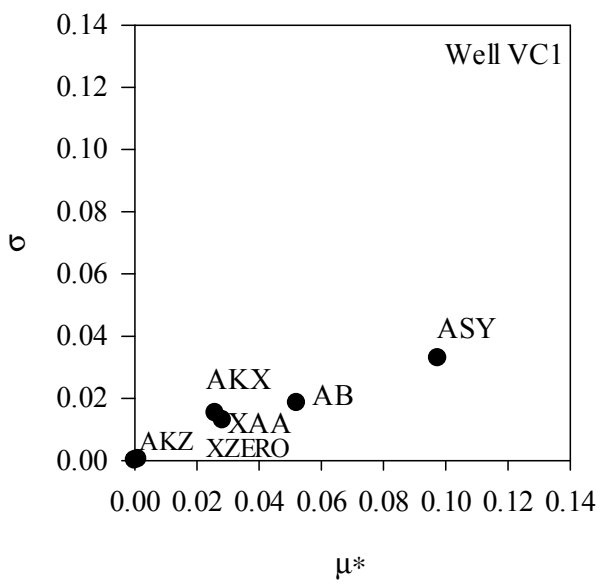

Figure 2. Morris screening results for STWT1 model applied in the Biscayne aquifer $(\mathrm{ASY}=\mathbf{s p e c i f i c}$ yield, $\mathrm{AB}=$ aquifer thickness, $\mathrm{AKX}=$ horizontal hydraulic conductivity, XAA = canal leakance, AKZ = vertical hydraulic conductivity, and XZERO = half canal width).

aquifer, Bolster et al. (2001) also indicated the sensitivity of water table elevations to specific yield especially during extreme fluctuations. Similarly, Kisekka and Migliaccio (2012) observed that MODFLOW-simulated water table elevation in the Biscayne aquifer was most sensitive to specific yield using PEST local sensitivity analysis.

The other model parameters positioned away from the origin of the $\mu^{*}-\sigma$ plane are aquifer saturated thickness, horizontal hydraulic conductivity, and canal leakance. Vertical hydraulic conductivity and half canal width were not important, given their location within the $\mu^{*}-\sigma$ plane (figs. 2 and 3). These results confirm that groundwater flow in the Biscayne aquifer is primarily horizontal, i.e., Dupuit assumptions are valid. Bolster et al. (2001) confirmed Dupuit assumptions for the Biscayne aquifer by placing piezometers at different depth at the same location and observed that there were no distinguishable differences in head measured by piezometers at different depths.

The sensitivity analysis approaches used in the previous studies did not provide qualitative relative rankings of all model parameters in the models applied to calculate water table elevation, as was achieved using the Morris method in this study. The practical application of the Morris results is directly related to management of flood events at the study 

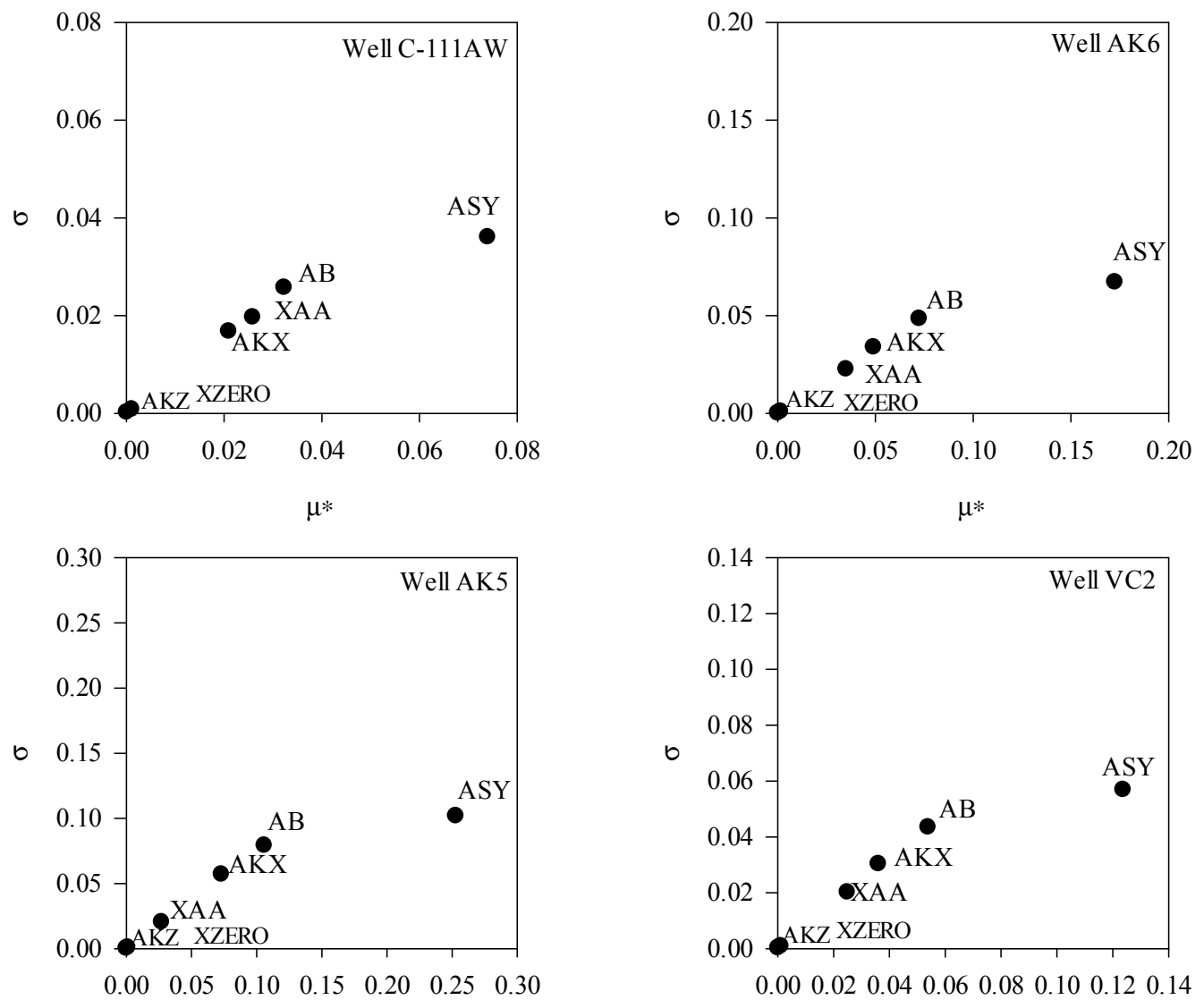

$\mu *$
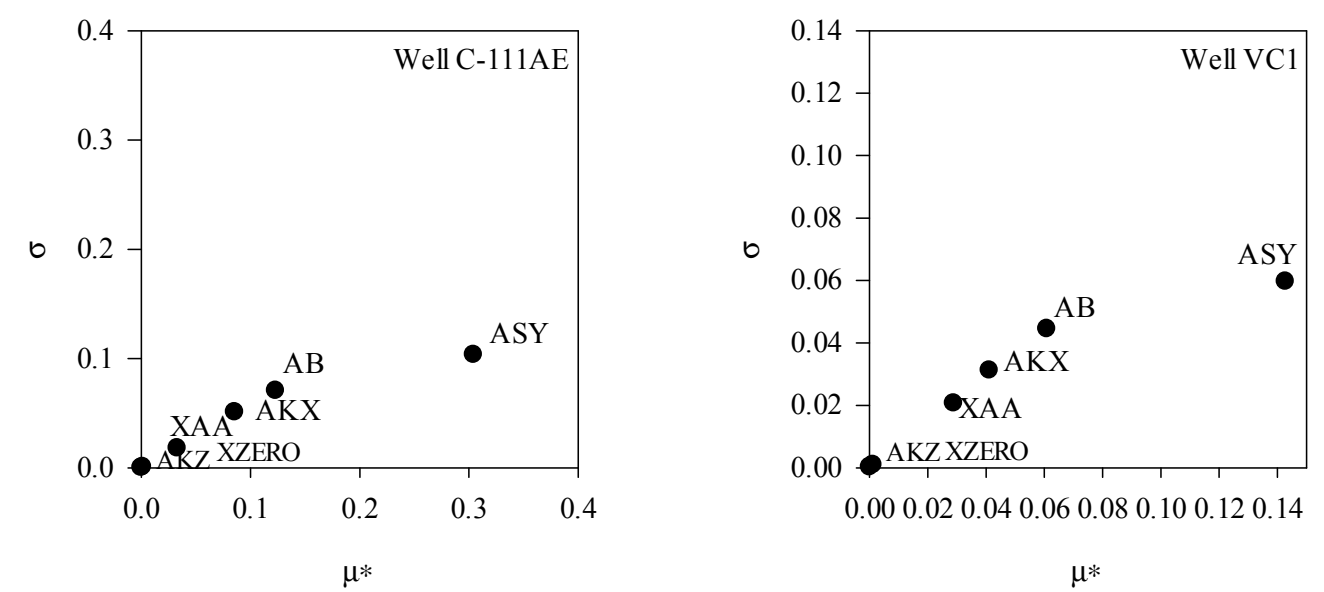

Figure 3. Improved Morris sampling screening results for STWT1 model applied in the Biscayne aquifer (ASY $=\mathbf{s p e c i f i c ~ y i e l d , ~ A B ~}=\mathbf{a q u i f e r}$ thickness, $A K X=$ horizontal hydraulic conductivity, XAA = canal leakance, AKZ = vertical hydraulic conductivity, and XZERO = half canal width).

area in which canal stage is usually lowered to create storage before a storm event, and the associated transient aquifer response is primarily influenced by specific yield. Therefore, properly characterizing Biscayne aquifer specific yield and its interactions with other parameters provides improved prediction of transient aquifer responses.

\section{GLOBAL SENSITIVITY ANALYSIS: SOBOL'S INDICES}

Based on Morris ranking of parameters, a subset of STWT1 important parameters, i.e., specific yield (ASY), horizontal hydraulic conductivity (AKX), aquifer thickness $(\mathrm{AB})$, and canal leakance (XAA), was used in further variance-based global sensitivity analysis using Sobol's method. Sobol indices were computed for the four parameters at the six groundwater observation wells. Figure 4 depicts the fraction of the total output variance explained by each of the four parameters using both firstorder and total Sobol sensitivity indices (vertical axis). For each parameter, the first-order effects are presented first, followed by the total effects, and the difference between the two represents higher-order effects or parameter inter- 
NSE Well C-111AW

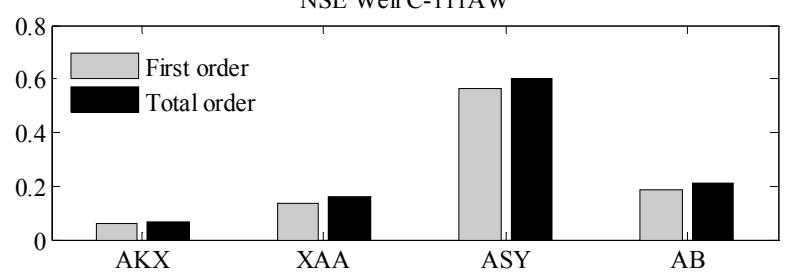

NSE Well AK6

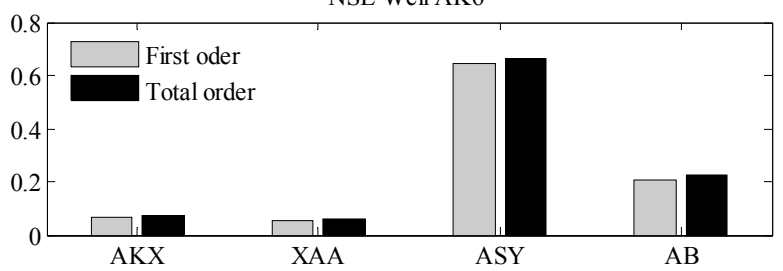

NSE Well C-111AE

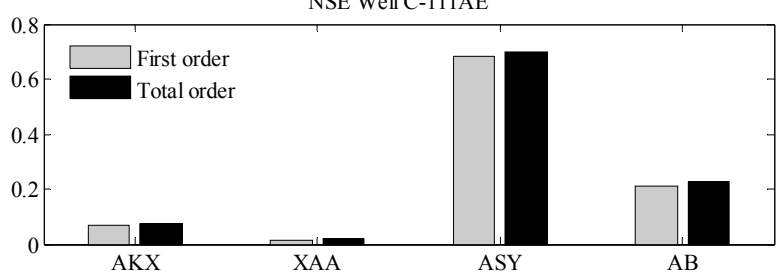

NSE Well AK5

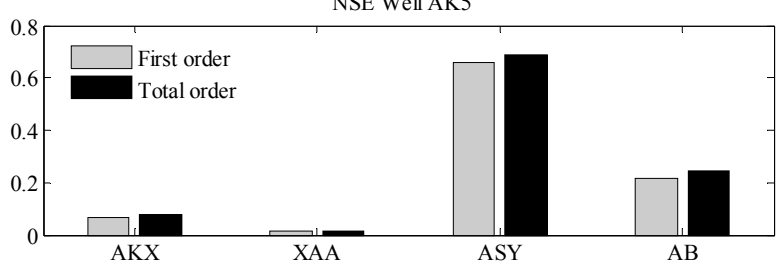

NSE Well VC2
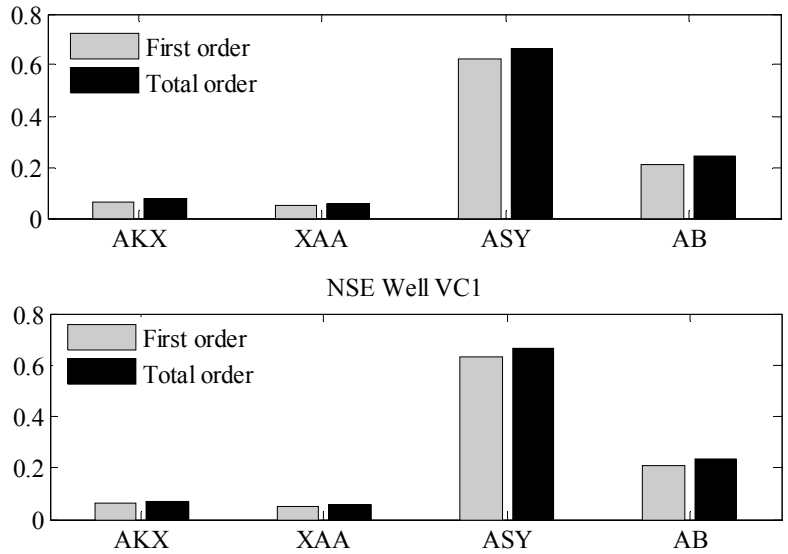

RMSE Well C-111AW

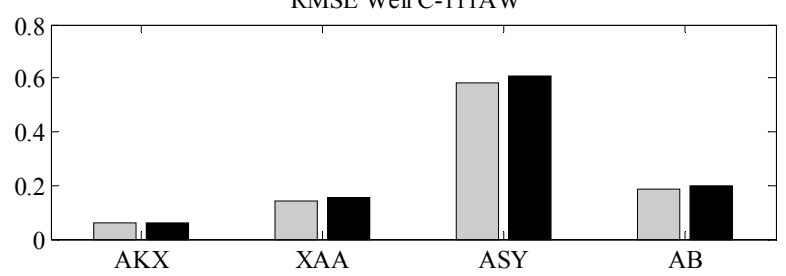

RMSE Well AK6

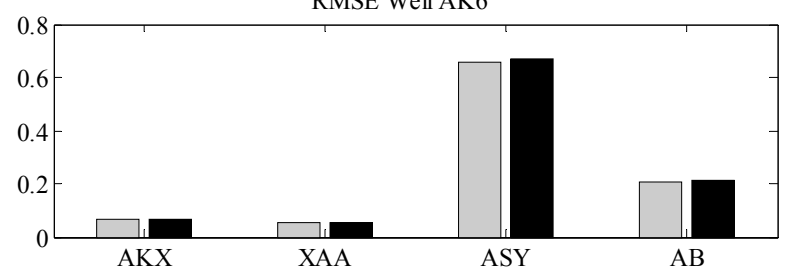

RMSE Well C-111AE

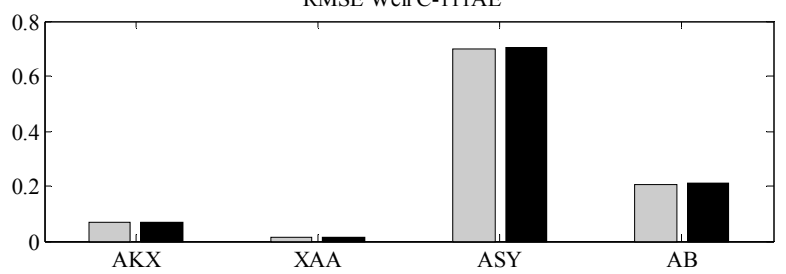

RMSE Well AK5

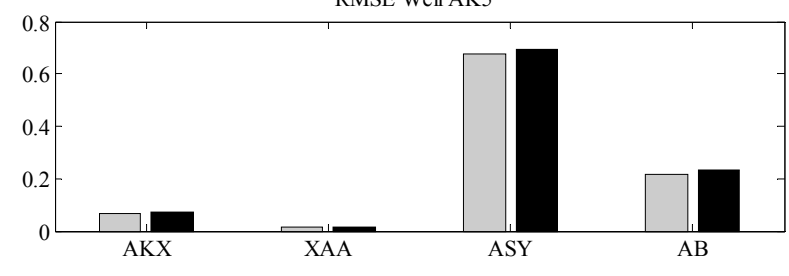

RMSE Well VC2

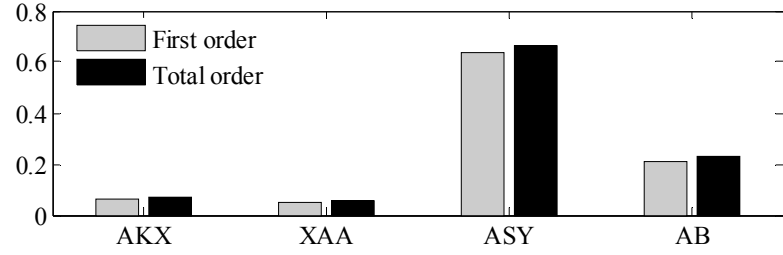

RMSE Well VC1

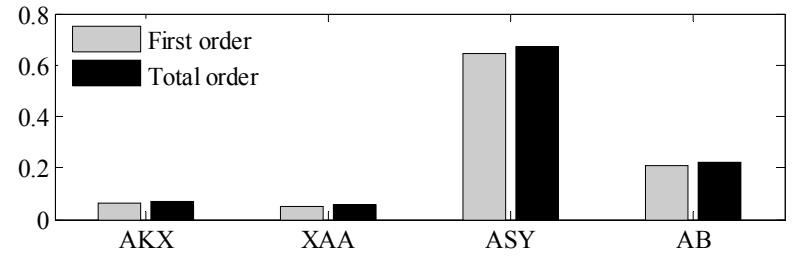

Figure 4. Sobol indices for the canal-aquifer interaction model STWT1 at six groundwater observation wells in the Biscayne aquifer (ASY= specific yield, $\mathbf{A B}=$ aquifer thickness, $\mathbf{A K X}=$ horizontal hydraulic conductivity, and XAA =canal leakance).

actions. Results from the Sobol analysis confirm and quantify results from the Morris analysis. At the six wells, specific yield explained over $60 \%$ of the total variance in predicted water table elevation (expressed using NSE and RMSE), followed by aquifer thickness explaining approximately $20 \%$. The results also show that the effect of canal leakance decreases as the distances from the canal increases (fig. 4), e.g., wells C-111AW and C-111AE are 500 and $2000 \mathrm{~m}$ from canal C-111, respectively. It is worth noting that the Sobol method is more robust than the Morris method since it is based on a large number of model simulations and a less structured sampling method (Saltelli et al., 2004; Muñoz-Carpena et al., 2007). Results from the Sobol analysis also indicate that the sum of all first-order parameter effects for the STWT1 model are approximately $100 \%$ (fig. 4), indicating that the STWT1 model behaves as an additive model. This implies that the STWT1 model can be efficiently calibrated if reliable data are available (Muñoz-Carpena et al., 2007).

\section{PARAMETER Estimation For STWT1 USING GLUE Parameter Uncertainty}

Posterior distributions for the four parameters at the six observation wells were produced for the 5120 model simu- 

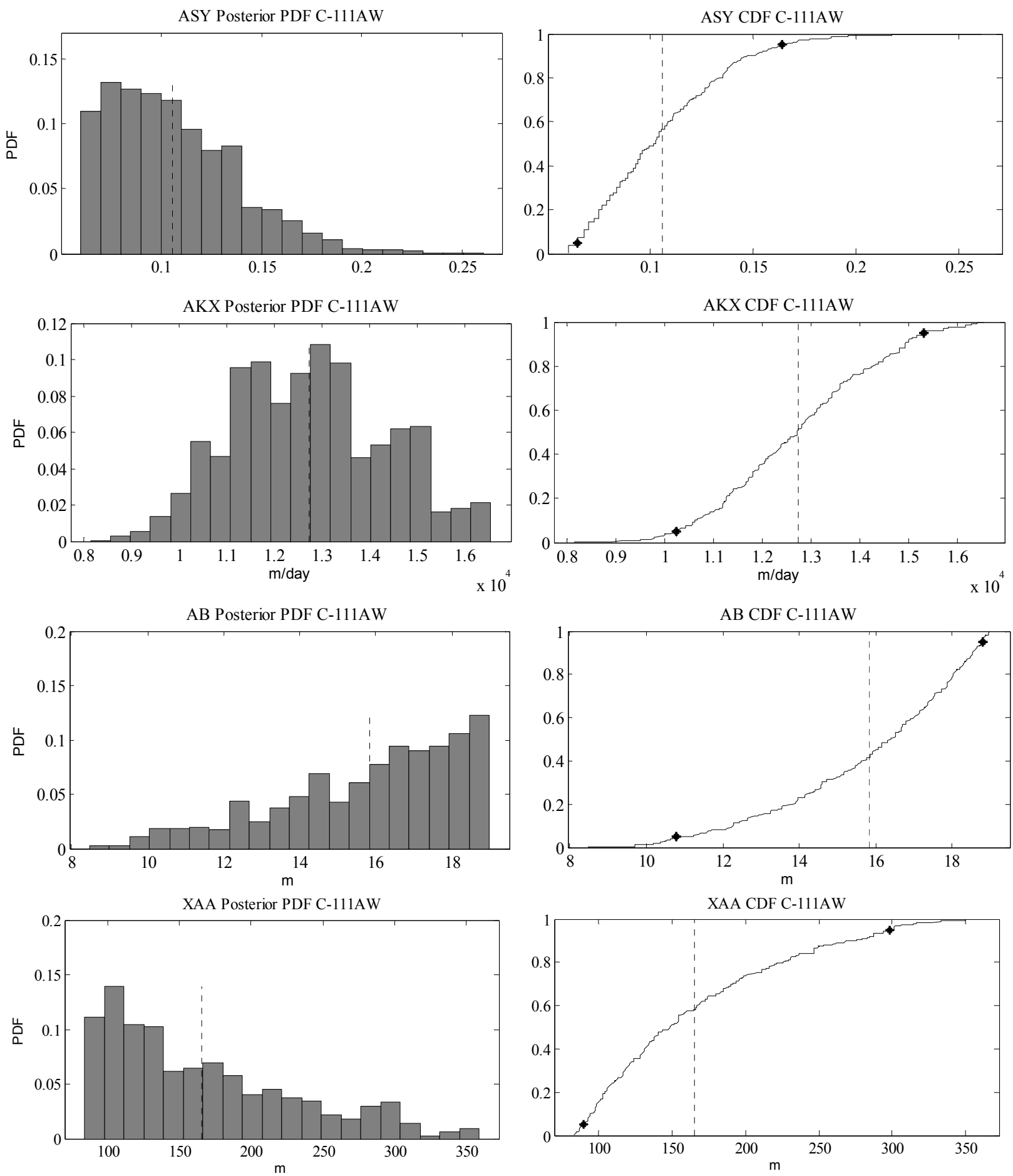

Figure 5. Posterior probability density functions (PDF) and cumulative density functions (CDF) for STWT1 model parameters estimated using GLUE. The dots on the CDF plots represent $5 \%$ and $95 \%$ quartiles for specific yield (ASY), horizontal hydraulic conductivity (AKX), aquifer thickness (AB), and canal leakance (XAA).

lations and for the top $10 \%$ (best performing in terms of fit between predicted and measured water table elevations) model simulations based on the likelihood measure NSE. In the following analysis, only posterior distributions corresponding to the top $10 \%$ of model simulations are presented. For brevity and to facilitate graphical representation, only histograms and CDF plots for wells C$111 \mathrm{AW}$ and $\mathrm{C}-111 \mathrm{AE}$ are shown in figures 5 and 6 . In the GLUE analysis, the shape of the posterior distributions also indicated the degree of uncertainty of the parameter estimates: sharp and peaked distributions are associated with well identifiable parameters, while flat distributions indicate greater parameter uncertainty. Posterior distributions for specific yield (ASY) were sharp and peaked, indicating less parameter uncertainty (fig. 5). AKX, AB, and XAA had less sharp and wider distributions compared to ASY, indicating more uncertainty compared to ASY. This is also confirmed by the standard deviations in 

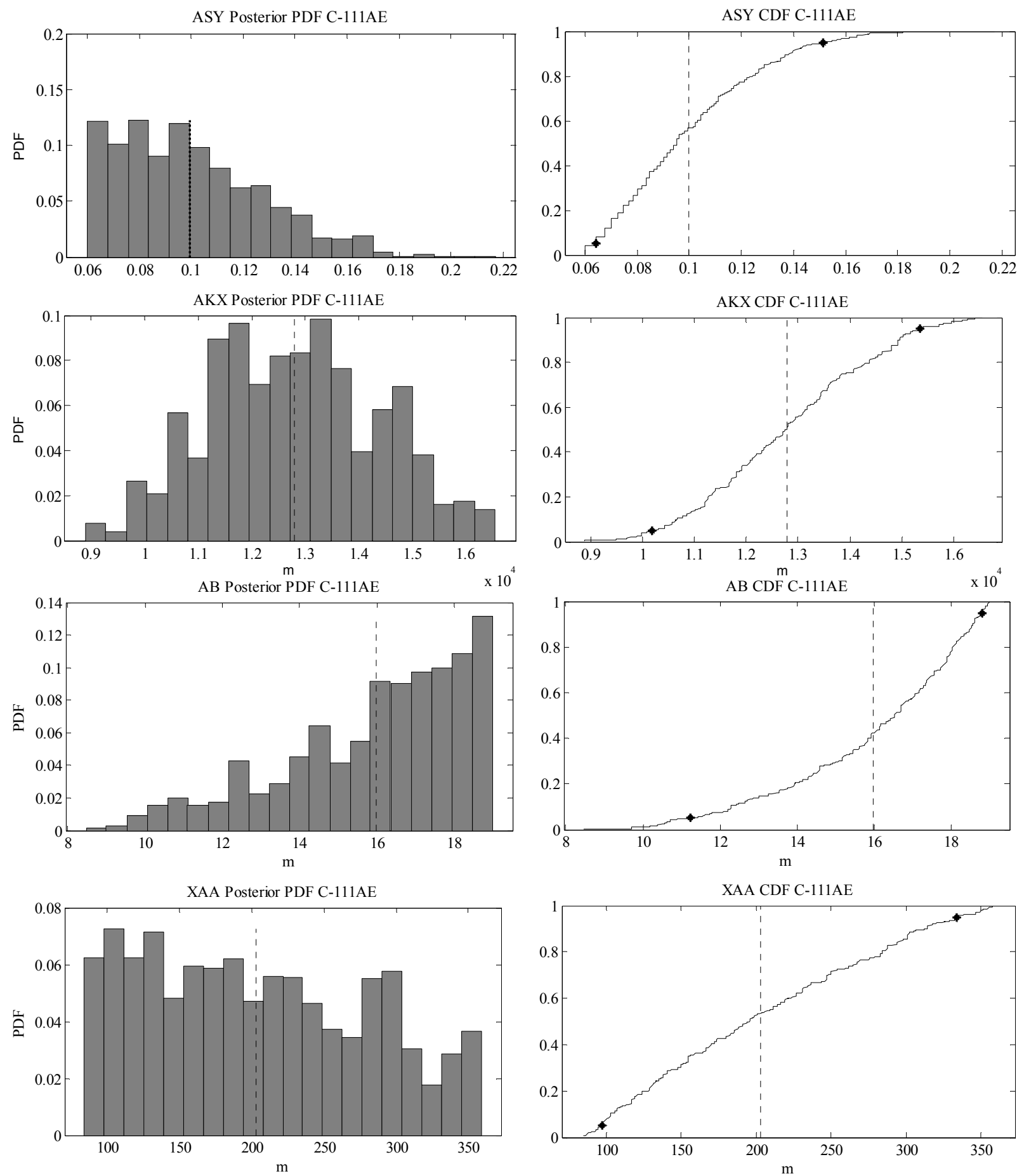

Figure 6. Posterior probability density functions (PDF) and cumulative density functions (CDF) for STWT1 model parameters estimated using GLUE. The dots on the CDF plots represent $5 \%$ and $95 \%$ quartiles for specific yield (ASY), horizontal hydraulic conductivity (AKX), aquifer thickness (AB), and canal leakance (XAA).

table 3. Again, for brevity, dot plots for only well C-111AW (fig. 7) are shown as an example, indicating that variation in NSE was greater for specific yield and to a less extent for saturated thickness (AB), AKX, and XAA. Model response to variation in the four parameters was similar at all the six sites, probably due to the small variation in water table elevation at the different wells. The posterior CDF plots show mean values as well as 5\% and $95 \%$ quintiles for the model parameters. GLUE-estimated parameters are shown in table 3.

\section{MODEL FIT}

From the posterior distributions, parameter estimates were inferred as model values corresponding to the top $10 \%$ or best model simulations with the highest likelihood measure, which in this study was NSE closest to 1.0. As an example, figure 8 shows good fit between measured and predicted water table elevations at three of the six wells along the same transect from canal C-111. Water table elevation was predicted using the STWT1 model, and parameters values were obtained from the GLUE analysis. 
Table 3. GLUE-estimated parameters for the canal-aquifer interaction model STWT1.

\begin{tabular}{|c|c|c|c|c|c|}
\hline Well & $\begin{array}{l}\text { Specific } \\
\text { Yield } \\
(\text { ASY) }\end{array}$ & $\begin{array}{c}\text { Horizontal Hydraulic } \\
\text { Conductivity } \\
\left(\mathrm{AKX}, \mathrm{m} \mathrm{d}^{-1}\right)\end{array}$ & $\begin{array}{c}\text { Aquifer } \\
\text { Thickness } \\
(\mathrm{AB}, \mathrm{m})\end{array}$ & $\begin{array}{c}\text { Canal } \\
\text { Leakance } \\
(\mathrm{XAA}, \mathrm{m}) \\
\end{array}$ & $\begin{array}{c}\text { Model } \\
\text { NSE }^{[\mathrm{a}]} \\
\text { Threshold }\end{array}$ \\
\hline C-111AW & $0.106 \pm 0.032$ & $12740 \pm 1598$ & $15.83 \pm 2.40$ & $165.6 \pm 65.85$ & 0.95 to 0.96 \\
\hline AK6 & $0.103 \pm 0.029$ & $12760 \pm 1611$ & $15.90 \pm 2.38$ & $187.5 \pm 73.47$ & 0.82 to 0.86 \\
\hline C-111AE & $0.100 \pm 0.028$ & $12790 \pm 1602$ & $15.97 \pm 2.34$ & $203.1 \pm 76.79$ & 0.81 to 0.90 \\
\hline AK5 & $0.100 \pm 0.027$ & $12780 \pm 1603$ & $15.96 \pm 2.35$ & $203.4 \pm 76.59$ & 0.66 to 0.70 \\
\hline $\mathrm{VC} 2$ & $0.102 \pm 0.029$ & $12770 \pm 1607$ & $15.92 \pm 2.37$ & $187.5 \pm 73.51$ & 0.80 to 0.82 \\
\hline VC1 & $0.102 \pm 0.029$ & $12770 \pm 1606$ & $15.92 \pm 2.36$ & $187.3 \pm 73.43$ & 0.76 to 0.80 \\
\hline
\end{tabular}

[a] $\mathrm{NSE}=$ Nash-Sutcliffe coefficient of efficiency
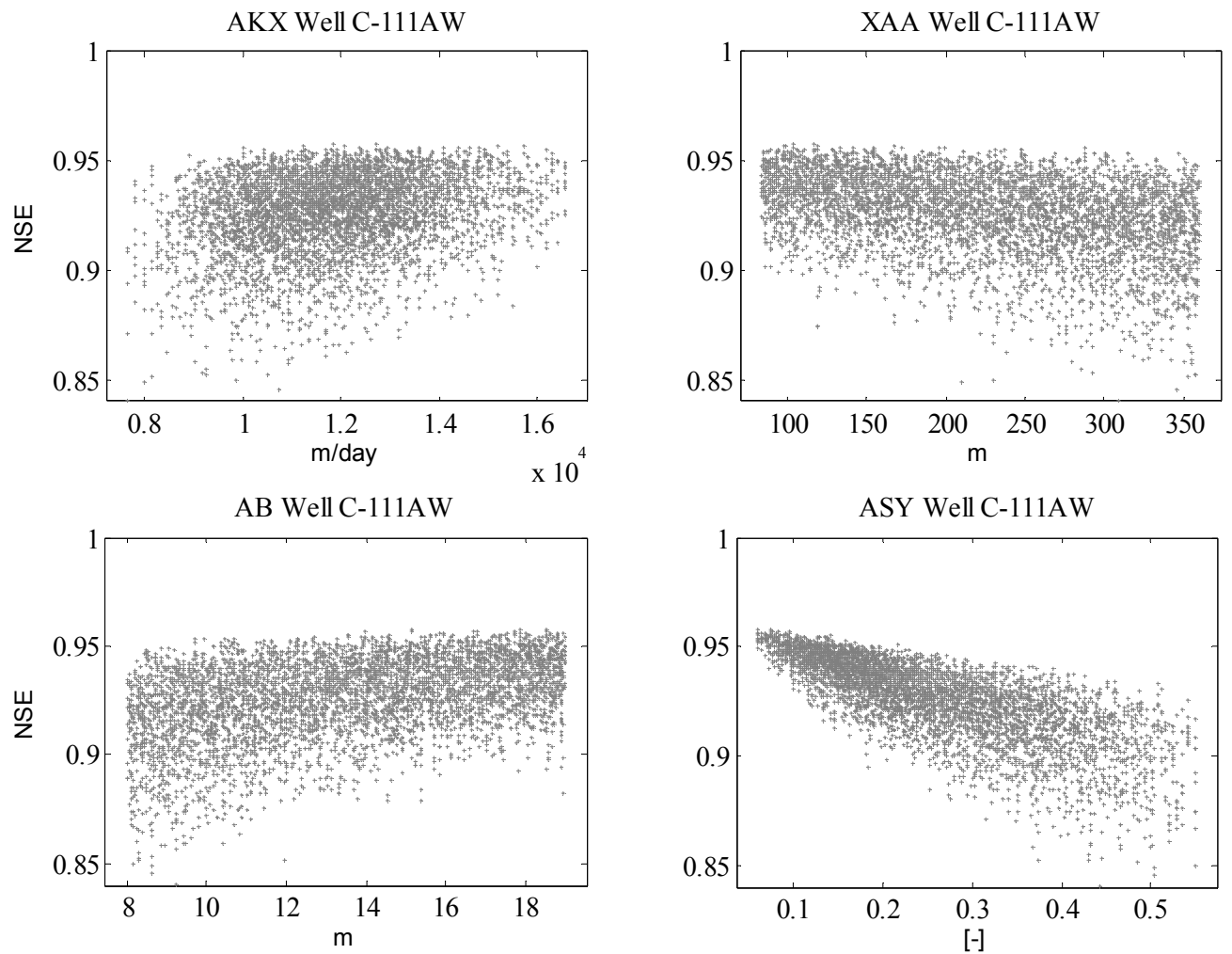

Figure 7. Dot plots from GLUE analysis showing change in the likelihood measure NSE (Nash-Sutcliffe coefficient) over the range of model parameters. The dots represent the 5120 model runs at well C-111AW.

The NSE values for all the wells are shown in table 3 . Accuracy of model fit decreased with increasing distance from the canal, from NSE of 0.95 at $500 \mathrm{~m}$ from the canal (C-111AW) to 0.81 at $2000 \mathrm{~m}$ from the canal (C-111AE). The RMSE also increased from $3.5 \mathrm{~cm}$ at $\mathrm{C}-111 \mathrm{AW}$ to 6.7 and $6.5 \mathrm{~cm}$ at AK6 and $\mathrm{C}-111 \mathrm{AE}$, respectively. This model behavior would be expected because the model assumes that, as distance from the canal becomes large, the change in water table elevation approaches the initial water table in the system. The model appears to be more accurate within distances of $2000 \mathrm{~m}$ from the canal. The GLUE results show that both the model and likelihood function used in this study were realistic.

\section{COMPARISON OF Estimated PARAMETERS TO Literature VALUES}

The value of specific yield estimated in this study is within the range of values estimated using other methods in the literature. In this study, we estimated an average specific yield of 0.10. Bolster et al. (2001) used a complex canal drawdown field experiment to estimate specific yield as 0.15 for the Biscayne aquifer near Everglades National Park. Muñoz-Carpena and Li (2003) used high temporal resolution (15 min interval) groundwater data to estimate specific yield near our study site by dividing precipitationbased recharge (after a large storm) by change in groundwater head along a transect in the Biscayne aquifer to obtain specific yield of 0.11 at several wells. Schroeder et al. (1958) reported specific yield values ranging between 0.1 and 0.35 for the Biscayne aquifer.

Table 3 shows that the values of horizontal hydraulic conductivity estimated in this study were within the range of 7,590 to $14,000 \mathrm{~m} \mathrm{~d}^{-1}$ obtained by Genereux and Guardiario (1998) using a large-scale canal drawdown experiment. Our values were closest to the values estimated by Fish and Stewart (1991) and Chin (1991), 12,187 and $12,500 \mathrm{~m} \mathrm{~d}^{-1}$, who used stepped-drawdown pumping tests and a transmissivity approach, respectively. Fish and Stewart (1991) explained the difficulty in estimating aquifer parameters such as hydraulic conductivity for very 

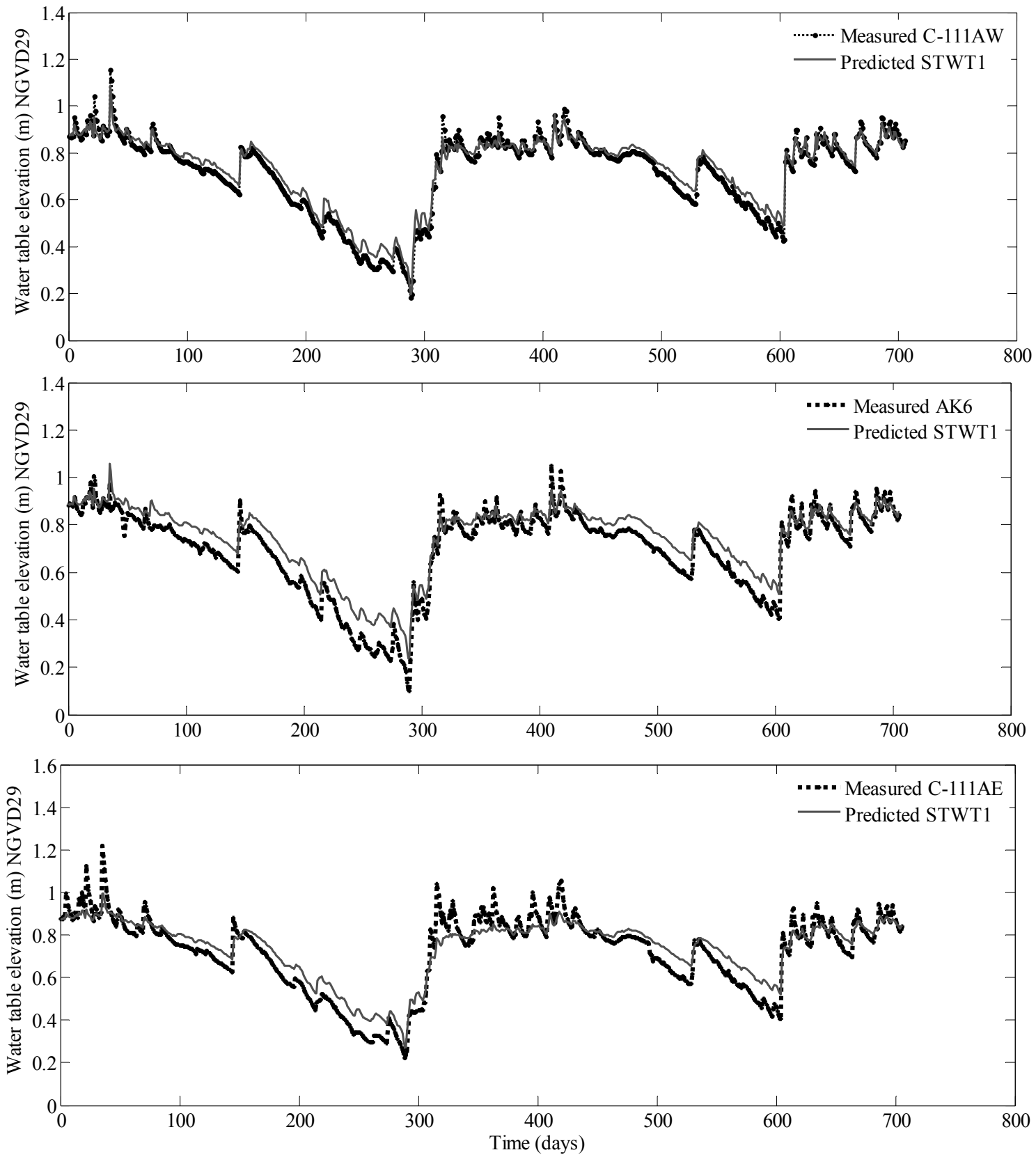

Figure 8. STWT1 predicted and measured water table elevation time series along a transect from canal C-111 at three wells located at distances 500,1000 , and $2000 \mathrm{~m}$ for wells $\mathrm{C}-111 \mathrm{AW}, \mathrm{AK6}$ and $\mathrm{C}-111 \mathrm{AE}$, respectively.

high-yielding aquifers such as the Biscayne aquifer. In their pumping test studies, aquifer water levels recovered within 1 to 2 min, which was too quick for practical measurements of drawdown. Therefore, the simple and inexpensive method employed in this study provides a globally based method for estimating aquifer parameters for high-yielding aquifers.

The estimated aquifer thickness at our study site is also within the range estimated by Bolster et al. (2001) west of $\mathrm{C}-111$ and is close to the approximate values of total thickness of the Biscayne aquifer estimated based on Fish and Stewart (1991). There is little literature on the values of C-111 canal leakance; however, our average value of 189 is close to the value of 148 estimated by Bolster et al. (2001) for the same canal. The similarity in the values estimated in this study using GLUE to values estimated using other methods confirms and provides confidence in our results. This work demonstrates a simple but robust procedure for characterizing parameters governing surface-groundwater interactions. The values estimated in this study can be used for predicting transient aquifer responses using more complex numerical models for flood event management, ecosystem management, and even water supply well field management.

\section{CONCLUSION}

Global sensitivity analysis using the Morris screening method (original and improved sampling) and Sobol's variance-based sensitivity analysis were applied to the 
STWT1 approximate analytical model of canal-aquifer interaction to assess the influence of parameters on the exchange of water between canal C-111 and the Biscayne aquifer and to better quantify selected physical parameters. Using the qualitative Morris method, important STWT1 parameters were ranked. Parameter rankings based on the original random sampling technique and the improved sampling strategy were the same, but the magnitudes of sensitivity measures were high for the latter, probably due to better characterization of parameter effects. Ranking indicated that only four parameters were important for explaining aquifer response to transient canal stage and recharge variations. Based on Sobol's analysis, specific yield was identified as the most important parameter explaining transient aquifer responses to stresses. STWT1 was determined to be an additive model; all parameters had primarily first-order effects, with negligible parameter interactions, implying that this model could be accurately calibrated using reliable measured data. Parameter values for the most sensitive parameters were estimated using the GLUE method. Posterior distributions from GLUE indicated sharp and narrow probability distributions for specific yield, implying that this parameter could be estimated with minimum uncertainty. The values of parameters estimated using GLUE resulted in good model fit, especially for wells within $2000 \mathrm{~m}$ of the canal, with $0.8<\mathrm{NSE}<0.95$ and RMSE less than $7 \mathrm{~cm}$. The estimated values were also close to values reported in the literature that were estimated using more complex field experiments. We expect that the parameter values determined in this study together with their probability distributions would be useful as starting values for numerical simulations or for quick prediction of transient aquifer responses using analytical models. The computational cost for global sensitivity analysis is never cheap. The total cost may not be obvious, but the expertise and resources required are expensive. However, these tools provide researchers with an idea of the key measurements that are needed to improve model predictions.

\section{ACKNOWLEDGEMENTS}

The authors would like to thank the South Florida Water Management District for providing the funding for this study, the University of Florida IFAS Tropical Research and Education Center, and the University of Florida Department of Agricultural and Biological Engineering, as well as Mr. Vito Strano and Mr. Sam Accursio for allowing us to use their lands, and Mrs. Tina Dispenza for her contribution to the data collection and processing. The authors would also like to thank the anonymous reviewers for providing suggestions that improved the manuscript.

\section{REFERENCES}

Allen, R. 2011. Ref-ET: Reference evapotranspiration calculation software. User manual. Kimberly, Ida.: University of Idaho, Idaho Agricultural Experiment Station.

Barlow, P. M., and A. F. Moench. 1998. Analytical solutions and computer programs for hydraulic interaction of stream-aquifer systems. USGS Open-File Report 98-415A. Marlborough,
Mass.: U.S. Geological Survey, Water Resources Division. Beven, K. 2006. A manifesto for the equifinality thesis. J. Hydrol. 320(1-2): 18-36.

Beven, K. J., and A. M. Binley. 1992. The future of distributed models: Model calibration and uncertainty prediction. Hydrol. Proc. 6(3): 279-298.

Bolster, C., D. Genereux, and J. Saiers. 2001. Determination of specific yield for a limestone aquifer from a canal drawdown test. Ground Water 39(5): 768-777.

Campolongo, F., J. Cariboni, and A. Saltelli. 2007. An effective screening design for sensitivity analysis of large models. Environ. Modeling and Software 22(10): 1509-1518.

Chan, K., A. Saltelli, and S. Tarantola. 1997. Sensitivity analysis of model output: Variance-based methods make the difference. In Proc. 1997 Winter Simulation Conference, 261-268. S. Andradóttir, K. J. Healy, D. H. Withers, and B. L. Nelson, eds. Piscataway, N.J.: IEEE.

Chan, K., S. Tarantola, A. Saltelli, and I. M. Sobol. 2000. Variancebased methods. In Sensitivity Analysis, 167-197. A. Saltelli, K. Chan, and M. Scott, eds. New York, N.Y.: John Wiley and Sons.

Chin, D. 1990. A method to estimate canal leakage into the Biscayne aquifer, Dade County, Florida. Water-Resources Investigations Report 90-4135. Tallahassee, Fla.: U.S. Geological Survey.

Chin, D. 1991. Leakage of clogged channels that partially penetrate surficial aquifers. J. Hydraul. Eng. 117(4):467-488.

Fish, J. E., and M. Stewart. 1991. Hydrogeology of the surficial aquifer system, Dade County, Florida. Water-Resources Investigations Report 190-4108. Tallahassee, Fla.: U.S. Geological Survey.

Freeze, R. A., and J. A. Cherry. 1979. Groundwater. Englewood Cliffs, N.J.: Prentice-Hall.

Frey, H. C., and S. R. Patil. 2002. Identification and review of sensitivity analysis methods. Risk Analysis 22(3): 553-578.

Genereux, D. P., and J. D. Guardiario. 1998. A canal drawdown experiment for determination of aquifer parameters. J. Hydrol. Eng. 3(4): 294-302.

Ha, K., D. Koh, B. Yum, and K. Lee. 2007. Estimation of layered aquifer diffusivity and river resistance using flood wave response model. J. Hydrol. 337(3-4): 284-293.

Hall, F. R., and A. F. Moench. 1972. Application of the convolution equation to stream-aquifer relationships. Water Resources Res. 8(2): 487-493.

Hantush, M. M. 2005. Modeling stream-aquifer interactions with linear response functions. J. Hydrol. 31(1-4): 59-79.

Kisekka, I., and K. W. Migliaccio. 2012. C-111 spreader canal phase 1 soil water and groundwater monitoring for planned S-18C water level increases. Report submitted to South Florida Water Management District as part of C-111 spreader canal project. Contract No. 4600002140. West Palm Beach, Fla.: South Florida Water Management District.

Krause, P., D. P. Boyle, and F. Base. 2005. Comparison of different efficiency criteria for hydrological model assessment. Advances in Geosci. 5: 89-97.

Lal, A. M. W. 2001. Modification of canal flow due to streamaquifer interaction. J. Hydraul. Eng. 127(7): 567-576.

Lal, A. M. W. 2006. Determination of multiple aquifer parameters using generated water level disturbances. Water Resources Res. 42(3): W03429, doi: 10.1029/2005WR004218.

Merkel, R. 2000. Element and sediment accumulation rates in the Florida Everglades. Water, Air, and Soil Pollution 122(3-4): $327-$ 349.

Moench, A. F., and P. M. Barlow. 2000. Aquifer response to stream stage and recharge variations: I. Analytical step-response functions. J. Hydrol. 230(3-4): 192-210.

Morris, M. D. 1991. Factorial sampling plans for preliminary 
computational experiments. Technometrics 33(2): 161-174.

Muñoz-Carpena, R., and Y. Li. 2003. Study of the Frog Pond area hydrology and water quality modifications introduced by the $\mathrm{C}$ 111 project detention pond implementation. Final project report. TREC-RMC-2003-01. Homestead, Fla.: University of Florida IFAS, Tropical Research and Education Center.

Muñoz-Carpena, R., Z. Zajac, and Y. M. Kuo. 2007. Global sensitivity and uncertainty analyses of the water quality model VFSMOD. Trans. ASABE 50(5): 1719-1732.

Olsthoorn, N. T. 2008. Do a bit more with convolution. Ground Water 46(1): 3-22.

Pathak, S. C. 2008. South Florida environmental report, Volume I: Appendix 2-1. West Palm Beach, Fla.: South Florida Water Management District.

Ruano, M. V., J. Ribes, A. Seco, and J. Ferrer. 2012. An improved sampling strategy based on trajectory design for application of the Morris method to systems with many input factors. Environ. Modeling and Software 37: 103-109.

Ratto, M., and A. Saltelli. 2001. Model assessment in integrated procedures for environmental impact evaluation: Software prototypes. Estimation of human impact in the presence of natural fluctuations, IMPACT Deliverable 18. Project IST-199911313. Brussels, Belgium: Joint Research Center of the European Commission.

Saltelli, A., K. Chan, and E. M. Scott, eds. 2000. Sensitivity Analysis. New York, N.Y.: John Wiley and Sons.

Saltelli, A., S. Tarantola, F. Campolongo, and M. Ratto. 2004. Sensitivity Analysis in Practice: A Guide to Assessing Scientific Models. Chichester, U.K.: John Wiley and Sons.

Saltelli, A., M. Ratto, S. Tarantola, and F. Campolongo. 2005. Sensitivity analysis for chemical models. Chem. Rev. 105(7): 2811-2827.

Saltelli, A., T. Andres, F. Campolongo, J. Cariboni, D. Gatelli, M. Ratto, M. Saisana, and S. Tarantola. 2008. Global Sensitivity Analysis: The Primer. Chichester, U.K.: John Wiley and Sons. Saltelli, A., F. Campolongo, and J. Cariboni. 2009. Screening important inputs in models with strong interaction properties. Reliability Eng. and Systems Safety 94(7): 1149-1155.

Schroeder, M. C., H. Klein, and N. D. Hoy. 1958. Biscayne aquifer of Dade and Broward Counties, Florida. Report of Investigations No. 17. Tallahassee, Fla.: U.S. Geological Survey. Available at: http://ufdc.ufl.edu/UF00001201/00001.

Serrano, S. E., and S. R. Workman. 1998. Modeling transient stream/aquifer interaction with the non-linear Boussinesq equation and its analytical solution. J. Hydrol. 206(3-4): 245255.

SimLab. 2004. Simulation environment for uncertainty and sensitivity analysis. Version 2.2. Brussels, Belgium: Joint Research Center of the European Commission.

Skinner, C., F. Bloetscher, and C. S. Pathak. 2008. Comparison of NEXRAD and rain gauge precipitation measurements in south Florida. J. Hydrol. Eng. 14(3): 248-260.

Sobol, I. M. 1993. Sensitivity estimates for non-linear mathematical models. Math. Modeling and Comp. Exp. 4(1): 407-414.

Stedinger, J. R., R. M. Vogel, S. Lee, and R. Batchelder. 2008. Appraisal of the generalized likelihood uncertainty estimation (GLUE) method. Water Resources Res. 44(12): W00B06, doi: 10.1029/2008WR006822.

Stehfest, H. 1970. Algorithm 368: Numerical inversion of Laplace transforms. Communications of the ACM 13(1): 47-49.

Vesselinov, V. V., G. Pau, and S. Finsterle. 2012. AGNI: Coupling model analysis tools and high-performance subsurface flow and transport simulators for risk and performance assessments. In Proc. XIX Intl. Conf. on Computational Methods in Water Resources (CMWR 2012). Urbana-Champaign, Ill.: University of Illinois.

Winter, T. C., J. W. Harvey, O. L. Franke, and W. M. Alley. 1998. Ground water and surface water: A single resource. USGS Circular 1139. Denver, Colo.: U.S. Geological Survey.

Zlotnik, V. A., and H. Huang. 1999. Effect of partial penetration and streambed sediments on aquifer response to stream stage fluctuations. Ground Water 37(4): 599-605. 